\title{
SITUATIONAL CONTROL OF HOT BLAST STOVES GROUP BASED ON DECISION TREE
}

\author{
Kobysh E.I. ${ }^{1}$, Simkin A.I. ${ }^{2}$ \\ ${ }^{1,2}$ State Higher Educational Institution "Priazovskyi State Technical University", Mariupol \\ E. mails: ${ }^{2}$ lena.kobysh@gmail.com \\ Copyright (C) 2014 by author and the journal “Automation technological and business - processes". \\ This work is licensed under the Creative Commons Attribution International License (CC BY). \\ http://creativecommons.org/licenses/by/4.0/
}
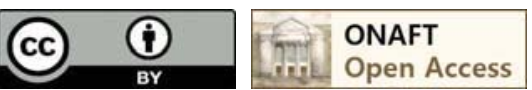

\begin{abstract}
In this paper was developed the control system of group of hot blast stoves, which operates on the basis of the packing heating control subsystem and subsystem of forecasting of modes duration in the hot blast stoves APCS of iron smelting in a blast furnace. With the use of multi-criteria optimization methods, implemented the adjustment of control system conduct, which takes into account the current production situation that has arisen in the course of the heating packing of each hot blast stove group. Developed a situation recognition algorithm and the choice of scenarios of control based on a decision tree.
\end{abstract}

Key words

hot blast stove, structural identification, parametric identification, fuzzy knowledge base, multi-criteria optimization, decision tree.

A group of hot blast stoves, which includes usually 3-4 regenerative heat exchanger, heats blast air to a temperature of $1000-1150{ }^{\circ} \mathrm{C}$. For the stable running of the blast furnace is necessary to ensure the constancy of the blast temperature by mixing the required amount of cold air to hot the stream. In the sequential mode of operation of the group of hot blast stoves one heater is located in a mode of blast heating, and others apparatus - in a mode of heating of regenerative chamber. Switching the hot blast stove from the blast heating mode in the regenerative chamber heating mode occurs at the closing of the mixing valve for cold air duct, when the temperature of hot air coming from the hot blast stove into the blast furnace reaches the set point temperature of the blast. Readiness of the next hot blast stove to switch to blast heating mode is estimated using temperature state of the regenerative chamber bottom. The hot blast stove is considered to be ready for switching to the blast heating mode when a temperature of the regenerative chamber bottom is $400{ }^{\circ} \mathrm{C}$.

In the preparation of hot blast at the block of hot blast stoves, there is a possibility of occurrence of situations in which the regenerative chamber heating process complicated by due to certain negative factors, for example, insufficient amount fuel and (or) its low calorie content in the case of using blast furnace gas without high-calorie supplements. Such situations may lead to insufficient heating of the regenerative chamber, and accordingly no fulfill the requirements of the technological card, which strictly defines the sequence of switching modes of each apparatus thus to ensure a continuous supply of hot blast into a blast furnace with a predetermined amount of and a predetermined temperature.

Analysis of the cycles of hot blast stoves operation is given in the paper [1]. In this paper investigated the dependence of the temperature distribution of the regenerative chamber height on the length of the blast heating and the regenerative chamber heating periods. There are considered the features of the block hot blast stoves operation in different modes and with different number of units in the group. In [2] presented the expert control system of regenerative chamber heating mode based on fuzzy logic. Fuzzy knowledge base consists of logical rules that take into account the parameters of the gas-coolant at the inlet to regenerative chamber, but completely regenerative chamber temperature condition over the entire height, which evaluation is only possible when considering the characteristics of the waste gases, is ignored. Also the proposed control system does not contain information about the current temperature state of the remaining hot blast stoves from the group that excludes the possibility of using this information for controlling the operation of the entire block of hot blast stoves. 
To ensure the readiness of each hot blast stove to timely switch modes it is possible to predict the duration of the current period of each heater of the group, based on assessment of the current temperature state of the regenerative chamber. The problem of forecasting the temperature state of the regenerative chamber using a three-layer neural network is solved in [3]. The accuracy of the prediction model is increased by introducing feedback. The disadvantage of the proposed model is the high computational complexity of neural network training algorithms. Partially solve the problem allows an approach to forecasting, based on the theory of fuzzy sets [4]. Application of the methods of data mining leads to limiting the number of association rules in the fuzzy knowledge base to necessary and sufficient minimum, and thus reduce the number of model settings.

In [5] the authors proposed the algorithm of regenerative chamber heating control with a gradual decrease in the consumption of high-calorie supplement during the heating process. The law of change the consumption of the fuel highcalorie supplements presented a function of two variables: the current dome temperature and the temperature of the bottom of the regenerative chamber. To systemize and to structure approach to the control of the regenerative chamber heating used an algorithm based on fuzzy knowledge base, proposed by the authors in paper [6]. The input parameters of fuzzy control model adopted by the dome temperature and the bottom of the regenerative chamber, the output parameter of the model - the current caloric of fuel mixture. This algorithm allows to efficiently control of the regenerative chamber heating, but to control the operation of the hot blast stoves group there is a need to obtain timely information on the current temperature state of the regenerative chambers of the other hot blast stoves in the group. Therefore, the expediency acquires the complex functioning of fuzzy control and forecasting models $[4,6]$, taking into account the current operating conditions of the hot blast stoves group.

The purpose of the article is to develop a strategy of quality situational control of hot blast stoves group based on decision tree using fuzzy knowledge bases, which tuning is carried out using multi-criteria optimization methods.

Input parameters of fuzzy control model of regenerative chamber heating were asked the following linguistic variables. For the dome temperature and the regenerative chamber bottom temperature: $T_{K l}, T_{H 1}-\ll$ low», $T_{\kappa 2}, T_{H 2}-$ «below the average», $T_{\kappa 3}, T_{H 3}$ - «average», $T_{\kappa 4}, T_{H 4}$ - «under the average», $T_{\kappa 5}, T_{H 5}$ - «high». Linguistic variables for the third input parameter (the predicted permissible duration of regenerative chamber heating period) are presented by values: $\tau_{1^{-}} \ll$ full period», $\tau_{2^{-}} \ll$ more than half of the period», $\tau_{3}-\ll$ the half of the period», $\tau_{4^{-}}$«less than half of the period», $\tau_{5^{-}}$«completion of the period».

Select of an output parameter of fuzzy control model depends on the heating method of the hot blast stove. In case of using high-calorie additive it is possible to change the total caloric content of the mixture by changing the consumption of one of the components of a fuel mixture. Since the total combustion heat depends mostly on the proportion of the content in a mixture of high-calorie supplement, as well as the purpose of economy the expensive high-calorie fuel, become expedient reduction of the caloric of the mixture during the heating of the regenerative chamber by reducing the percentage of highcalorie fuel additives. When heating a hot blast stove only low-calorie fuel, which is usually used blast furnace gas, change the heat of combustion is not possible. Therefore, the most rational solution in this case is to control the heating of the regenerative chamber by changing the fuel consumption. In this way, the output parameter of fuzzy control model of regenerative chamber heating is the current fuel consumption. The general scheme of the computer complex of control and forecasting is shown in fig. 1.

When implementing control and forecasting subsystems based on fuzzy knowledge bases is necessary to solve problems of structural and parametric identification. Structurally fuzzy knowledge base is represented by a set of association rules of the form "if-then", the extraction of which from the experimental data is possible with the help of Data Mining Method. Association rules and permissible combinations of input parameters for the fuzzy knowledge bases of the regenerative chamber heating control subsystem and subsystem of predict the duration of the hot blast stove work periods are extracted from the experimental data using the algorithm of data mining Apriori in software package STATISTICA. 


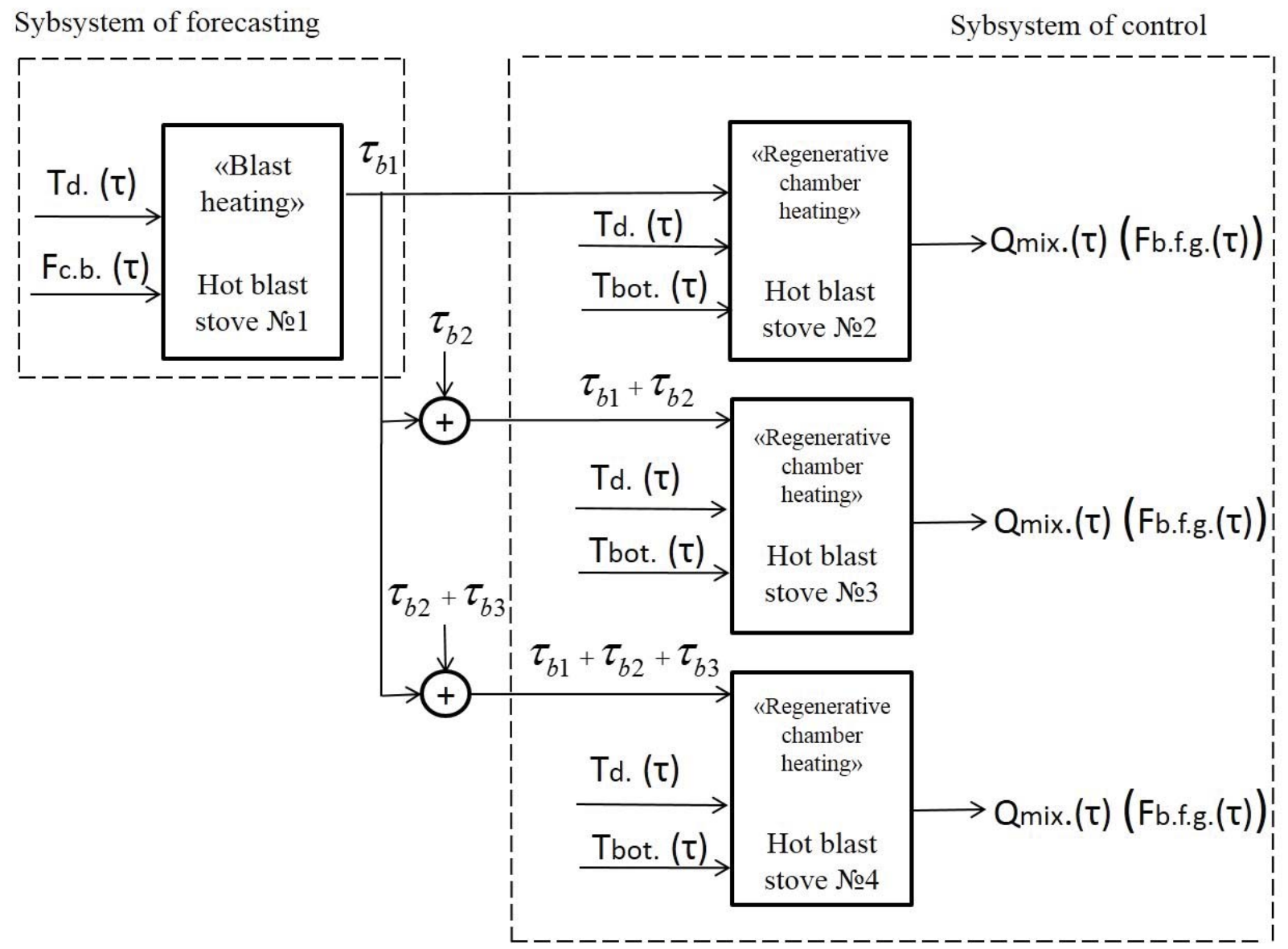

Fig. 1 - The general scheme of the complex of forecasting and control of the hot blast stoves group, based on fuzzy logic

Parametric identification is to find the parameters of fuzzy control and forecasting models, in which the simulation result is closest to the desired. To this end, for the prediction subsystem is carried the tuning of fuzzy knowledge bases, which is the solution of the problem of multidimensional optimization:

$$
R=\sqrt{\frac{1}{M} \sum_{i=1}^{M}\left(y_{i}-\mathrm{f}\left(\bar{x}_{i}, \bar{w}, \bar{c}, \bar{b}\right)\right)^{2}} \rightarrow \min
$$

where $M-$ number of pairs of experimental data $\left(\bar{x}_{i}, y_{i}\right)$;

$\bar{w}$ - vector of weighting factors in the fuzzy rules;

$\bar{b}, \bar{c}$ - vectors of the parameters, presented by coordinate of the maximum and concentration factor of the membership function.

This problem is solved by the method of conjugate gradients with Polak-Ribiere recalculation formula [8]. Restriction of values of the weighting factors, characterizing the measure of the reliability of each association rule fuzzy knowledge base and located in the range $[0,1]$, is implemented by the method of penalty functions.

Tuning of the fuzzy control model of regenerative chamber heating is also a problem of multidimensional optimization, in which the selection of the objective function expedient for carrying out according to the current values of the parameters of the gas-heat medium and the temperature status of all the regenerative chambers of the hot blast stoves group. In the process of controlling the operation of the hot blast stoves group there is possibility for task and estimation of the quality of governance in accordance with the various, sometimes conflicting parameters, the main ones are the financial costs of fuel, deviations in time of working of each hot blast stove from the technological card (insufficient or premature heating of the regenerative chamber at the time of switching) and the amount of heat loss from the flue gases. Due to the physical heterogeneity of said parameters and the potential opportunity of occurrence of situations in which these parameters could be mutually exclusive, produce the tuning of fuzzy control model of regenerative chamber heating for the additive criterion, which is the algebraic sum of all these parameters, it is not possible. The solution to this problem lies in the choice of the multi-criterion optimization method. Taking into account the above features of the local optimization criteria is expedient to implement the tuning of fuzzy control model using the method of $\varepsilon$-restrictions, in which the multi-criterion optimization problem is reduced to the conditional one-criterion optimization by selecting the main criterion and setting range of admissible values for other local criteria. 
In connection with the above, the task of tuning fuzzy control model of regenerative chamber heating of each hot blast stove of the group for heating using only blast furnace gas in terms of economy of financial cost for fuel is formulated as follows:

$$
\begin{aligned}
& R_{c}=C_{\text {b.f.g. }} F_{b . f . g .} \rightarrow \min , \\
& R_{\text {dur. }}=\sum_{i=0}^{n-1} \tau_{b i}-\left(\tau_{\text {r.c. }}+\tau_{\text {sw. }}\right), \tau_{\text {sw. }} \leq R_{\text {dur. }}<\tau_{\text {sw.max }}, \\
& R_{\text {los. }}=Q_{\text {c.g. }}<Q_{\text {c.g.max. }}
\end{aligned}
$$

where $C_{\text {b.f.g. }}$ - blast furnace gas cost, UAH./m².;

$F_{b . f . g .}$ - the total consumption of the blast furnace gas for regenerative chamber heating period, $\mathrm{m}^{3}$;

$\tau_{b .}, \tau_{r . c .}, \tau_{s w .}, \tau_{s w . m a x}$ - the durations of periods of the blast heating and the regenerative chamber heating, average and maximum switching time of valves, $\mathrm{s}$;

$Q_{\text {c.g.. }}, Q_{\text {c.g.max. }}$ - actual and the maximum amount of heat carried away by combustion gases for the period of regenerative chamber heating, GJ.

When used for heating the hot blast stoves gas mixture (as a high-calorie supplements selected natural gas) the main optimization criterion includes two components:

$$
R_{c .}=C_{b . f . g .} F_{b . f . g .}+C_{n . g .} F_{n . g .} \rightarrow \min ,
$$

where $C_{n . g .}$ - nature gas cost, UAH. $/ \mathrm{m}^{3}$;

$F_{n . g .}$ - the total consumption of the nature gas for regenerative chamber heating period, $\mathrm{m}^{3}$.

In this case, there is the variant of select as the objective function of one of the components of sum or bringing a problem to the one-criterion by the method of conditional center of mass. When implementing this method, two optimization problems must be solved in sequence:

$$
R_{\text {c.b.f.g. }}=C_{\text {b.f.g. }} F_{\text {b.f.g. }}=f_{\text {b.f.g. }}\left(\bar{x}_{\text {b.f.g. }}\right) \rightarrow \min , R_{\text {c.n.g. }}=C_{\text {n.g. }} F_{n . g .}=f_{\text {n.g. }}\left(\bar{x}_{n . g .}\right) \rightarrow \min ,
$$

where $\bar{x}_{b . f . g .}, \bar{x}_{n . g \text {. }}$ - settings vectors: weights and parameters of membership functions, by minimizing costs for the blast furnace gas, and natural gas, respectively.

The coordinates of the conditional center of mass defined as follows:

$$
m_{\text {b.f.g. }}=\frac{R_{\text {c.b.f.g. }}+R_{\text {c.n.g. }}}{R_{\text {c.b.f.g }}}, m_{\text {n.g. }}=\frac{R_{\text {c.b.f.g. }}+R_{\text {c.n.g. }}}{R_{\text {c.n.g. }}} .
$$

The resulting vector of model settings determined according to the equation:

$$
\bar{x}=\frac{m_{b . f . g .} \bar{x}_{b . f . g .}+m_{n . g .} \bar{x}_{n . g .}}{m_{b . f . g .}+m_{n . g .}} .
$$

A significant advantage of the method of conditional center of mass is the possibility of taking into account the sensitivity of the coordinates of the desired parameter vector to each of the local optimization criteria. The main requirement for the implementation of this method is the uniformity of local criteria. For the task represented by the equations (4) - (6), this condition is met.

Situations, the occurrence of which is potentially possible in the process of regenerative chamber heating are described in the parent nodes of decision tree (Fig. 2). 


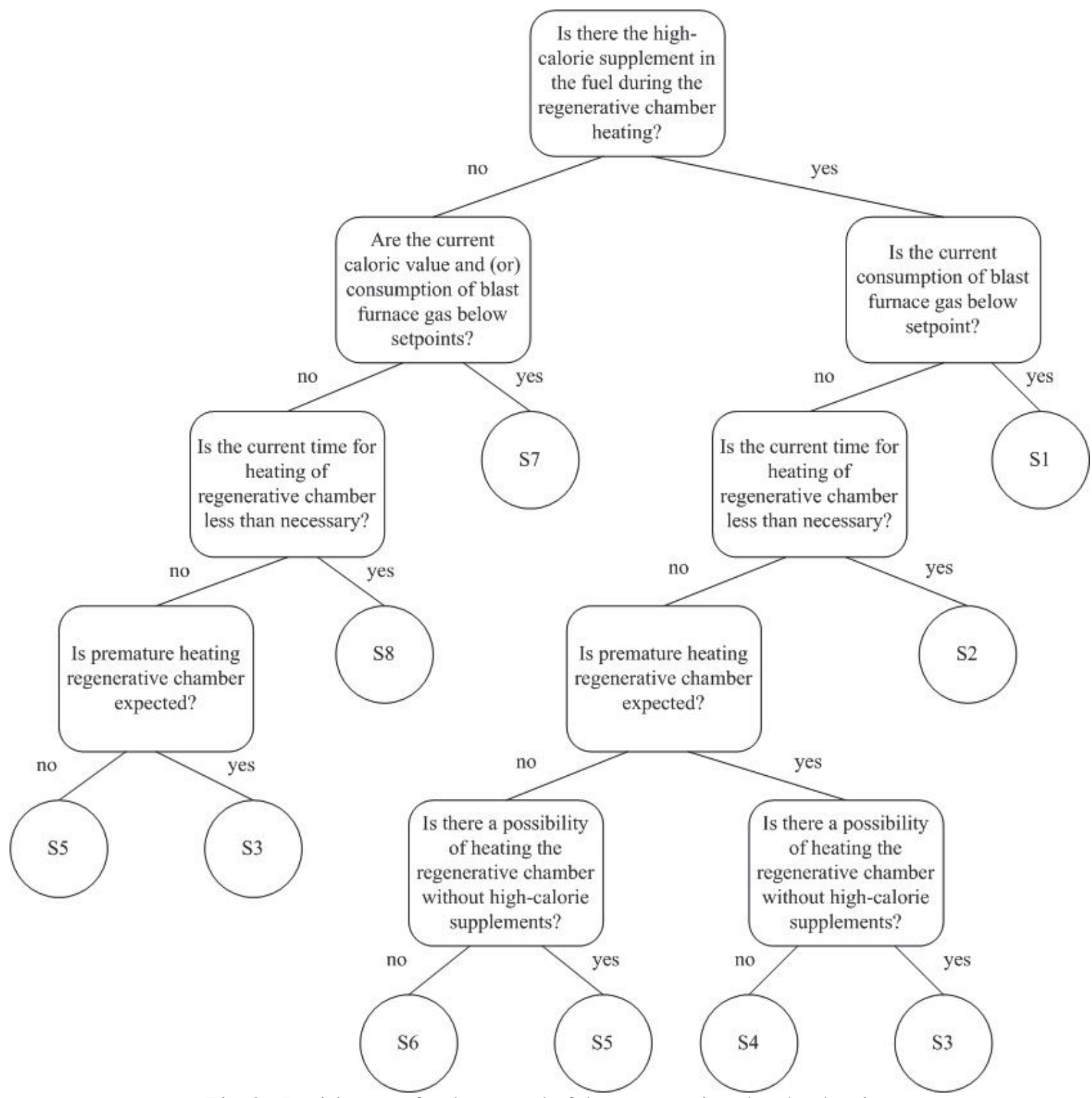

Fig. 2 - Decision tree for the control of the regenerative chamber heating

In the leaves of the decision-tree are the appropriate scenarios of the regenerative chamber heating control (S1-S8, Fig. 2), presented by fuzzy knowledge bases, structural identification of which is implemented using algorithms of data mining, and parametric identification - by tuning of each fuzzy knowledge base using the methods of the multi-criterion optimization, which described by equations (2) - (6).

For the left branch output parameters of fuzzy control models presented by the current value of the blast furnace gas consumption. An exception is the node containing the S7 control script, for which the control of regenerative chamber heating is with the greatest possible consumption of the blast furnace gas. To the right branch output parameters of fuzzy control model is the current value the heat of combustion of the fuel mixture. The exception is the nodes of S3 and S5, for which the output parameter of model is the consumption of main low-calorie fuel. For the parent nodes, describing the situation of the expected insufficient or premature heating of the regenerative chamber, choice of the further way by the tree is carried out according to the predicted values of the permissible and expected duration of the regenerative chamber heating period, obtained as a result of operation of forecasting subsystem, functioning on the basis of fuzzy set theory [4].

For a group of four blast stoves that have the same structural and thermal characteristics, was made a number of computer experiments, the results of which in the form of graphs describing the regenerative chamber heating control process shown in Fig. 3-4. 

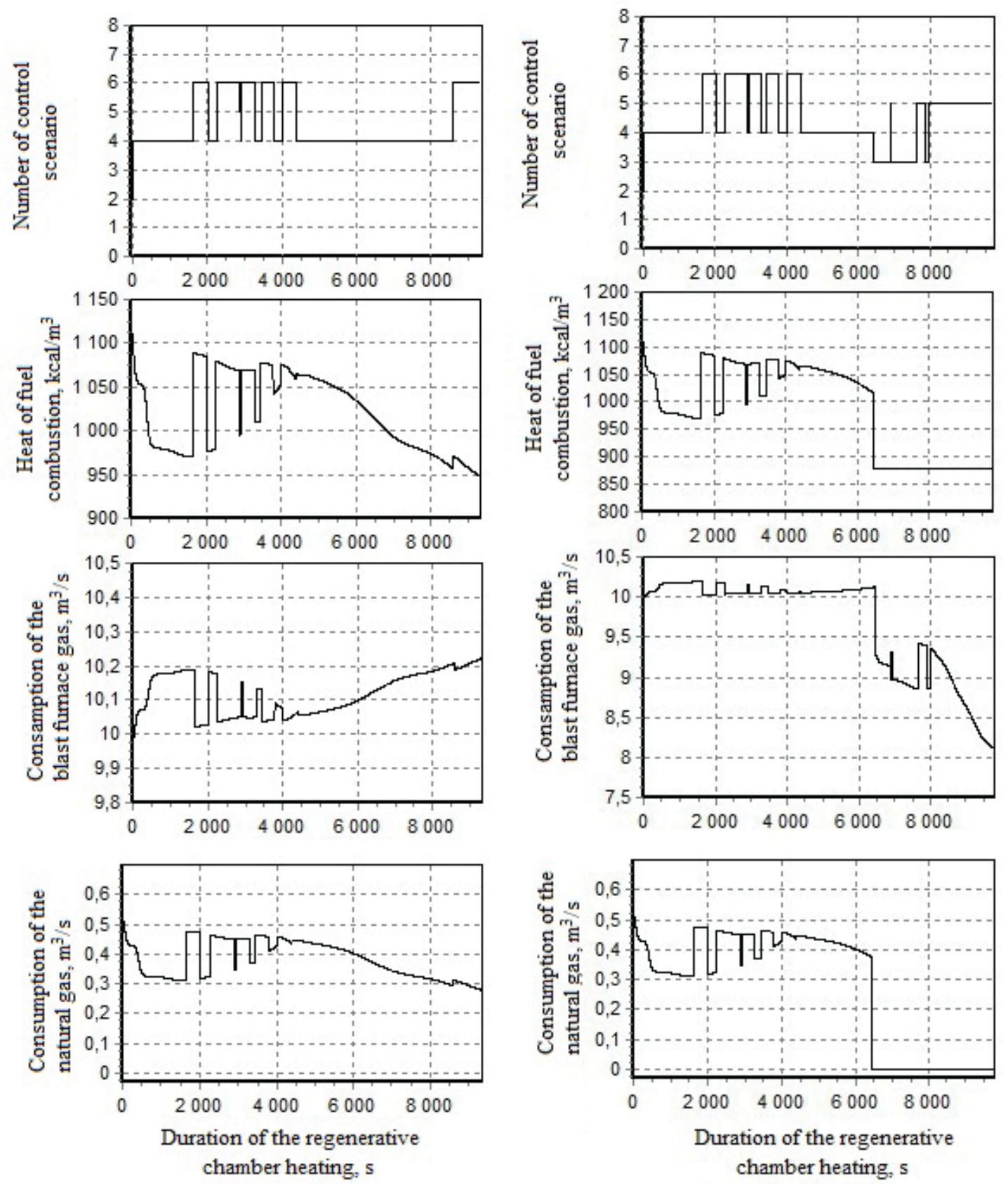

b

Fig. 3 - Graphs of change the control scenarios and the output parameters of fuzzy control models for experiment №1 (a) and for experiment №2 (b) 

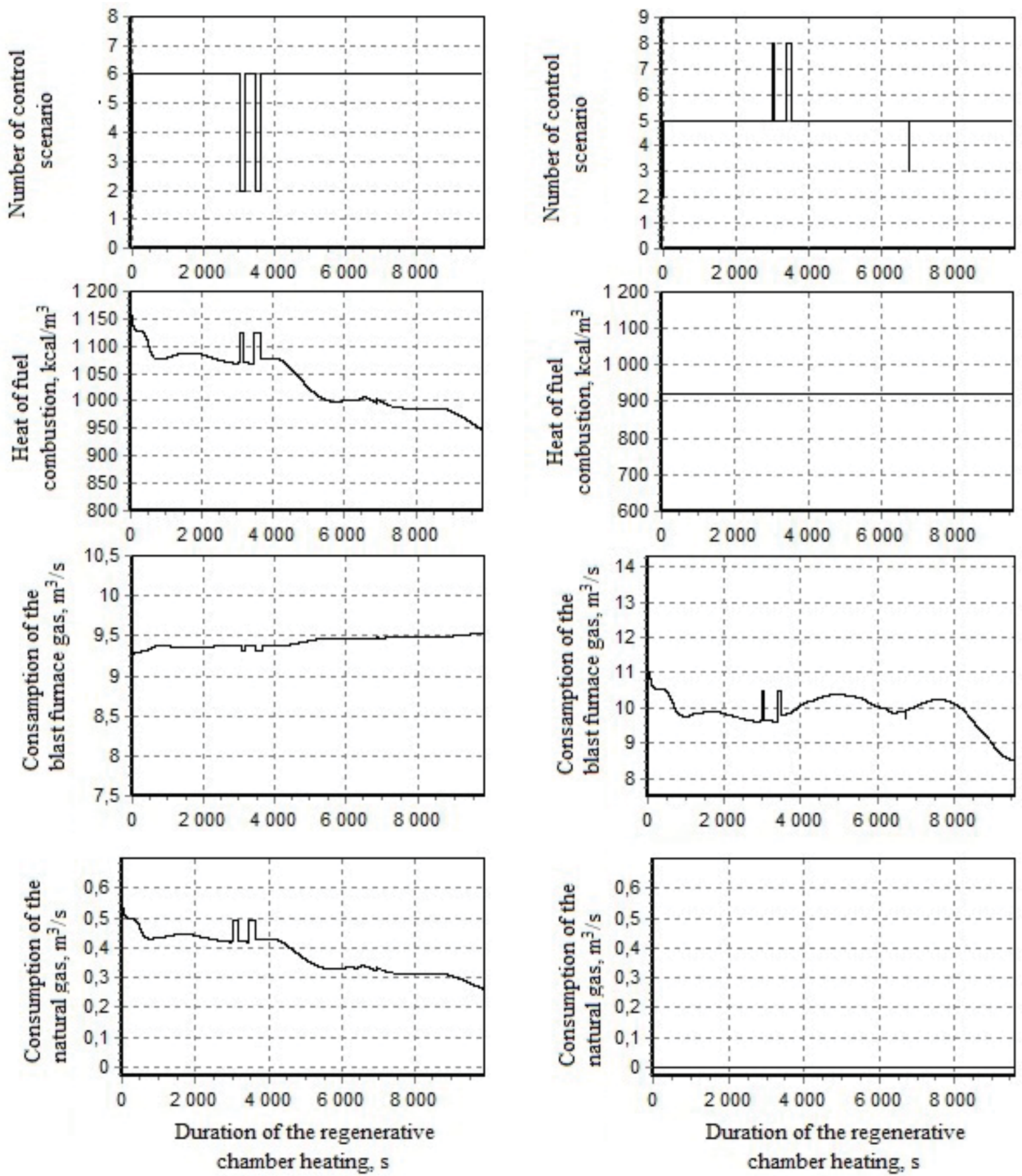

b

Fig. 4 - Graphs of change the control scenarios and the output parameters of fuzzy control models for experiment №3 (a) and for experiment №4 (b)

To estimate the quality of the results of the operation provided situation control system was introduced the additive coefficient accounting for the values obtained for all local criteria described by the equations (2) - (4). For ensure the dimensionless coefficients was carried the normalization of all terms by dividing by the maximum possible value of each component:

$$
K=\frac{R_{c .}}{R_{\text {c.max }}}+\frac{R_{\text {dur. }}}{R_{\text {dur.max }}}+\frac{R_{\text {los. }}}{R_{\text {los.max }}},
$$

where $R_{\text {c.max }}$ - the maximum possible value of the financial costs of fuel for the regenerative chamber heating period, UAH;

$R_{\text {dur.max }}$ - maximum possible value of the deviation from the duration of the mode set in the technological card, s; 


$$
R_{\text {los.max }} \text { - the maximum possible value of heat loss from the combustion gases, GJ. }
$$

Range of permissible values criterion described equation (7) is in the range $[0,3]$. The work area of values taken by criterion covers the range $[1.75 ; 3]$. Since in the equations (2) - (6) are solved the problem of minimization function, then the lower value of the criterion (7) indicates a higher quality of the control system.

Testing of control system based on decision tree was performed in the conditions with set value of dome temperature $1350^{\circ} \mathrm{C}$ and the set temperature of blast air $1150^{\circ} \mathrm{C}$. The results of computer simulation of the situational control system of the regenerative chamber heating with appropriate the control scenarios according of current situation are shown in the Table 1.

Table 1 - Results of the control system operation

\begin{tabular}{|c|c|c|c|c|}
\hline Parameter & $\begin{array}{l}\text { Experiment } \\
\text { №1 }\end{array}$ & $\begin{array}{l}\text { Experiment } \\
\quad № 2\end{array}$ & $\begin{array}{c}\text { Experiment } \\
\text { №3 }\end{array}$ & $\begin{array}{c}\text { Experiment } \\
\quad \text { №4 }\end{array}$ \\
\hline $\begin{array}{l}\text { Total consumption of the blast furnace gas for the } \\
\text { period of regenerative chamber heating, } \mathrm{m}^{3} / \mathrm{s}\end{array}$ & 94369,8 & 94457,1 & 93012,5 & 95265,8 \\
\hline $\begin{array}{l}\text { Total consumption of the natural gas for the period } \\
\text { of regenerative chamber heating, } \mathrm{m}^{3} / \mathrm{s}\end{array}$ & 3563,6 & 2640,5 & 3723,3 & - \\
\hline $\begin{array}{l}\text { The cost of blast furnace gas for the period of } \\
\text { regenerative chamber heating, UAH. }\end{array}$ & 65115,16 & 65175,4 & 64178,63 & 65733,4 \\
\hline $\begin{array}{c}\text { The cost of natural gas for the period of regenerative } \\
\text { chamber heating, UAH. }\end{array}$ & 27796,08 & 20595,9 & 29041,74 & - \\
\hline $\begin{array}{l}\text { Total cost of fuel for the period of regenerative } \\
\text { chamber heating }\left(\mathrm{R}_{c},\right), \mathrm{UAH} \text {. }\end{array}$ & 92911,24 & 85771,3 & 93220,37 & 65733,4 \\
\hline $\begin{array}{c}\text { Duration of the period of the regenerative chamber } \\
\text { heating, } \mathrm{s}\end{array}$ & 9327 & 9758 & 9871 & 9599 \\
\hline Duration of the period of the blast heating, $\mathrm{s}$ & 3441 & 3431 & 3462 & 3375 \\
\hline $\begin{array}{l}\text { Deviations in time for the one operation cycle of hot } \\
\text { blast stove according to the }(2),\left(\mathrm{R}_{\mathrm{dur}}\right), \mathrm{s}\end{array}$ & 396 & 65 & 85 & 74 \\
\hline $\begin{array}{l}\text { The amount of heat carried away from the } \\
\text { regenerative chamber of the combustion products, GJ }\end{array}$ & 56,4 & 56,5 & 56,6 & 56,6 \\
\hline $\begin{array}{c}\text { The amount of heat transferred to the hot blast during } \\
\text { blast heating period, GJ }\end{array}$ & 363,4 & 362,3 & 365,6 & 356,4 \\
\hline Additive criterion of the control quality & 2,25 & 1,83 & 2,13 & 1,99 \\
\hline
\end{tabular}

As seen from Table 2 and Figure 3, in process of heating of regenerative chamber with using the mixed gas as a result of transition to the blast furnace gas at a certain moment of the heating (Experiment №2), total consumption of expensive natural gas to the heating period is reduced to $923.1 \mathrm{~m}^{3}$, which leads to a decrease of total expenses for the heating period in the 7140 UAH. This choice of the control scenario is only possible with sufficient caloric blast furnace gas, which value has increased in the process of regenerative chamber heating for the experiment №2 from 750 to $880 \mathrm{kcal} / \mathrm{m}^{3}$. Experiment № 3 (Fig. $4 \mathrm{a}$ ) was held in the conditions close to the potentially possible probability of insufficient regenerative chamber heating, so for this experiment observed the highest total consumption of natural gas, and accordingly, the highest cost of the mixed gas to the heating period. The experiment №4 (Fig. 4 b) was held in the conditions of using only low-calorie fuel - blast furnace gas. 
Total fuel costs in this case are the lowest, but avoid the insufficient heating of regenerative chamber is only possible in the case of a sufficiently high calorific value of blast furnace gas, which value for the experiment was $920 \mathrm{kcal} / \mathrm{m}^{3}$.

Conclusions

1. As a result of structural and parametric identification are formed the fuzzy knowledge bases on the basis of rules of the form "if-then". The structure and parameters of each formed fuzzy knowledge base ensure the implementation of the control scenario of the regenerative chamber heating, taking into account the production situation at the moment for each of the hot blast stove from the group. The input parameters of the fuzzy knowledge bases are the current values of the dome temperature and the regenerative chamber bottom temperature, and the predicted value of time during which the hot blast stove may be in the mode of heating of regenerative chamber. Select an output parameter of fuzzy knowledge bases is carried out depending on the type of fuel used. When heating with a mixed gas, output parameter of fuzzy knowledge base is the calorific value of the gas mixture, for heating with the blast furnace gas the consumption of blast furnace gas.

2. Was held the setting of fuzzy knowledge bases using the methods of multi-criterion optimization. As local criteria selected for the total period of the heating regenerative chamber is the fuel costs, the total for the cycle of the hot blast stove deviation in time from the technological card, as well as the total for the regenerative chamber heating period, the heat loss from the leaving gases. Taking into account the features of local criteria, multi-criterion optimization is realized by $\varepsilon$-restrictions. In case of using mixed gas leading to the main criterion of optimization that takes into account the cost of the two components of the gas mixture is carried out by the method of conditional center of mass.

3. To select the control algorithm of the heating of regenerative chamber was constructed a decision tree that contains two main branches: the case of blast furnace gas heating and heating of regenerative chamber with a mixture of highcalorie and low-calorie components. In the process of situational control system operation is continuously carried out bypassing the tree and selection the appropriate control scenarios, presented by the fuzzy knowledge base of paragraph 1, configured using the methods described in paragraph 2.

4. In conducting computer experiments taking into account the emergence of different situations stipulated in the structure of a decision tree, it is determined that timely switching of control scenario avoids the possibility of insufficient or premature heating of the regenerative chamber (maximum deviation in time did not exceed 7 minutes, which is $3.1 \%$ of the total cycle time of operation of the hot blast stove). With the current value of calorific more than $830 \mathrm{kcal} / \mathrm{m}^{3}$ and a sufficient amount of blast furnace gas is possible rejection of the high-calorie supplements, as a result, it is estimated computer testing, control system leads to cost savings for the regenerative chamber heating period in the amount of $7140 \mathrm{UAH}$.

5. Continuous operation of the developed situational control system of blast stoves group as part of the APCS of iron smelting in a blast furnace allows carrying out the choice of the effective scenario of the control of the regenerative chamber heating, based on decision tree according to the multi-criterion optimal control strategy.

\section{References}

[1] Li Zhi, Wen Zhi, Su Fu-yong Analysis of efficient operating cycles for blast-furnace stoves // Metallurgist. - 2013. - Vol. 56. - P. 799-806.

[2] Hongwei GUO, Bingji YAN, Jianliang ZHANG, Shanshan CHEN Fuzzy control expert system of hot blast stove based on simulation and thermal balance // Metalurgia. - 2013. - № 1. - P. 10-17.

[3] Yaowu Tang, Xiang Liu Hot blast stove temperature control system based on neural network predictive control // Applied Mechanics and Materials. - 2015. - Vol. 709, - P. 281-284.

[4] Kobysh E.I., Simkin A.I. Subsystem of prediction the duration of heating blast period in hot blast stove based on fuzzy knowledge base // Metall I lit’e Ukrainy. - 2016. - №6. - P. 10-17.

[5] Kobysh E.I., Simkin A.I., Kravchenko V.P. Algoritm upravlenija nagrevom nasadki domennogo vozduhonagrevatelja s vnutrennej kameroj gorenija // Stal'. - 2014. - № 1. - P. 9-13.

[6] Kobysh E.I., Simkin A.I. Control model of the heating hot blast stove regenerative chamber based on fuzzy knowledge with training set // Metallurgical and Mining Industry. - 2015. - No. 6. - P. 96-101.

[7] Kobysh O.I., Simkin O.I., Koifman O.O. Computer model of blast stoves // Reporter of the Priazovskyi state technical university. Collections of scientific works - Mariupol, 2012. - Issue. 25. - P. 239-245.

[8] Hajkin S. Neural networks. A comprehensive foundation. Moscow, $-2006,-1104$ p. 